\title{
Treatment and Conservation of Six Egyptian Archaeological Stone Sarcophagi
}

\author{
Mohamed K. Khallaf I \& Ragab A. Mohamed ${ }^{\text {II }}$
}

\section{An abstract}

Tel El - Deir (tēl āl-dịr) is an archaeological site in Damietta governorate (Egypt), where many stone sarcophagi were excavated. This paper deals with the treatment and conservation processes of the selected six sarcophagi. Examinations and analyses of stone sarcophagi samples were studied using different scientific methods; firstly Petrography study by a polarizing microscope which shows that limestone consists mainly of calcite, beside fossils, iron oxides, clay minerals and some fine grained quartz. Secondly, scanning Electron Microscope (SEM) examination which shows that the crystals were worn out by the effect of the dissolving of some components, loose the binding materials between grains by the effect of salt crystallization, cavities and finally, micro cracks. Thirdly, X-Ray diffraction (XRD) analysis which shows that limestone consists of calcite, dolomite, and quartz in addition to halite traces. The restoration and conservation processes of these objects were carried out using mechanical cleaning, chemical cleaning, extraction of salts, the collecting of disintegration parts, completing of missing parts and consolidation and isolation processes.

\section{An introduction:}

Damietta is known in ancient Egyptian times as Dami or Damit, as Tamati in Coptic and as Tamamates in Greek. It became Damietta in European languages and in Arabic. In ancient times, it was a part of Smabhdt Nome, a region of Lower Egypt, where the Amun (God of Thebes) was worshiped. It bears number (050109) in the atlas of archaeological sites of Damietta, ${ }^{1}$ and it is considered as one of its important archaeological hills (tilalal). It is located in Kafr Saad; new Damietta city in the northeast of Kafr El- Batekh, No. (19). The Six stone sarcophagi have been covered in the form of human form. These objects were exposed to many deterioration factors. ${ }^{2}$ They were seriously affected by the archaeological environment due to the burial in soil which leads to different deterioration phenomena, fig (1). ${ }^{3}$ Due to the contact between the stone and the soil, it undergoes chemical, physical and mechanical weathering processes. Soil is the mixture of minerals, organic matter, gasses, liquids and a myriad of micro- and macro organisms. ${ }^{4}$ The soil texture is determined by the relative proportions of sand, silt and clay in the soil. The addition of organic matter, water, gases and time causes the combination to develop into a larger soil structure called an aggregate. ${ }^{5}$ At that point a soil can be said to be developed that can be described further in terms of color, porosity, consistency, reaction etc. ${ }^{6}$ Of all the factors influencing the evolution of soil, water is the most powerful due to its involvement in the solution, erosion, transportation and deposition of the materials of which a soil is composed. ${ }^{7}$ The mixture of water and dissolved and suspended materials is called the soil solution. ${ }^{8}$ Since soil water is never pure water, but contains hundreds of dissolved salts, organic and inorganic substances; it may be more accurately called the soil

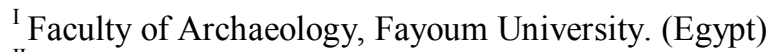

${ }^{\text {II }}$ Faculty of Archaeology \& Tourism Guidance, Misr University: MUST. (Egypt).
} 
solution. ${ }^{9}$ When these sarcophagi were excavated, some of them did not contain any fractures or cracks, while others were broken into two halves or into several parts and some of them had micro cracks, fig. (2). Stone sarcophagi deteriorated because of many deterioration factors, for example, the effect of soil in the burial environment, changes in moisture and temperature, opening of sarcophagi and transferring processes from the site to the museum store. This study aims to study the mineral composition, the deterioration phenomena and introduces a scientific study for restoration and conservation processes of these six archaeological stone sarcophagi which have covers in human form.

\section{State of stone sarcophagi at Tel El- Raba museum store before conservation:}

The six stone sarcophagi suffered from many deterioration phenomena for example, dirt on the surface, stains and crystallization of salts, broken into two halves and broken into several parts as it shown in table (1). Fig. (3a-f).
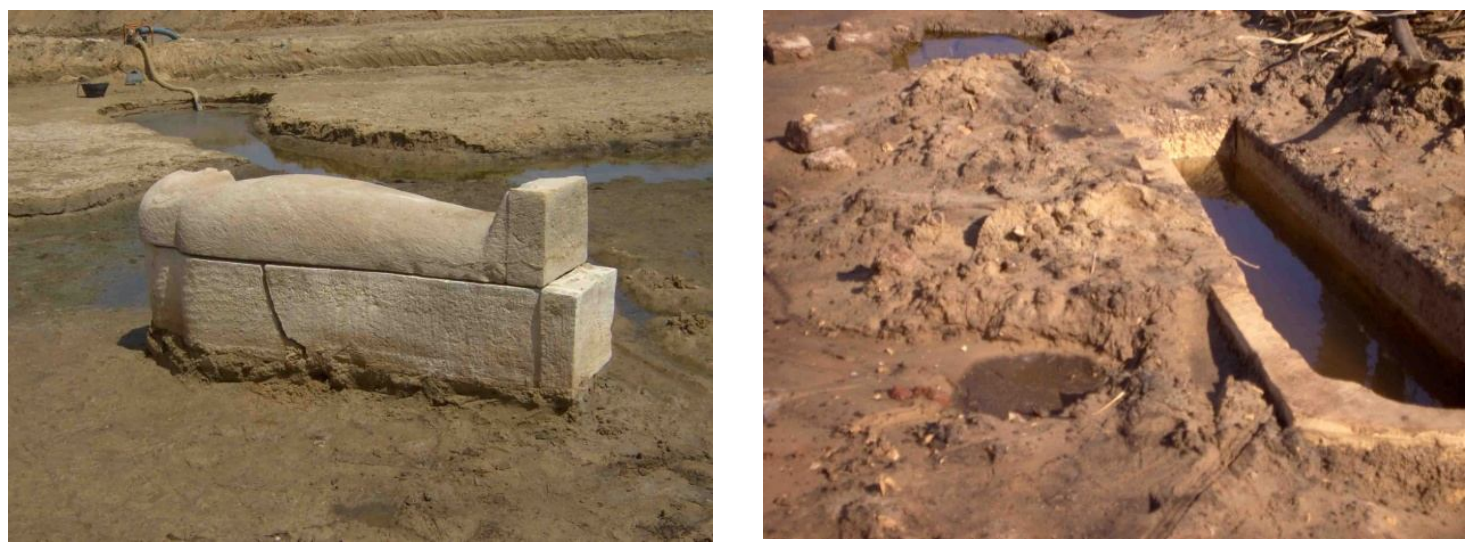

Fig. (1) Shows the stone sarcophagi in the excavation area at Tel El-Deir.

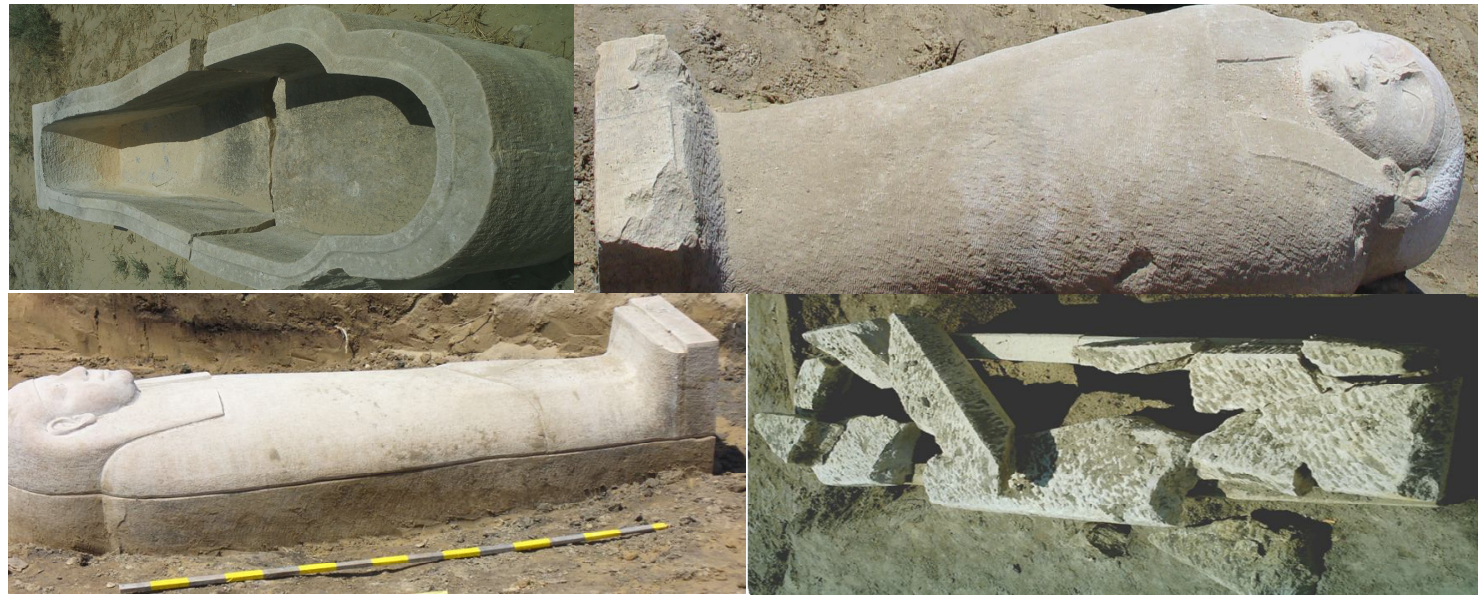

Fig. (2) Shows the state of Stone Sarcophagi after being excavated at Tel El- Deir site which had micro cracks and were broken into two halves or into several parts. 
Table (1) shows the state of the stone sarcophagi at Tel El-Raba museum store before the conservation processes:

\begin{tabular}{|l|l|}
\hline Sarcophagus & \multicolumn{1}{c|}{ Deterioration phenomena } \\
\hline No. 1 & $\begin{array}{l}\text { Dirt on the surface, crystallization of salts and the cover was broken } \\
\text { into seven parts. Fig. (3-a). }\end{array}$ \\
\hline No. 2 & $\begin{array}{l}\text { Dry clay stains; the cover was broken into two parts and efflorescence } \\
\text { of salts. Fig. (3-b). }\end{array}$ \\
\hline No. 3 & $\begin{array}{l}\text { Crystallization of salts on the base, clay stains and the cover was } \\
\text { broken into two parts. Fig. (3-c) }\end{array}$ \\
\hline No. 4 & $\begin{array}{l}\text { The base was broken into two parts from the center, crystallization of } \\
\text { salts and clay dirt. Fig. (3-d) }\end{array}$ \\
\hline No. 5 & $\begin{array}{l}\text { It was broken into several parts, stains, clay dirt and crystallization of } \\
\text { salts. Fig. (3-e). }\end{array}$ \\
\hline No. 6 & $\begin{array}{l}\text { Dirty surfaces, crystallization of salts and the cover and the base were } \\
\text { broken into several parts. Fig. (3-f). }\end{array}$ \\
\hline
\end{tabular}
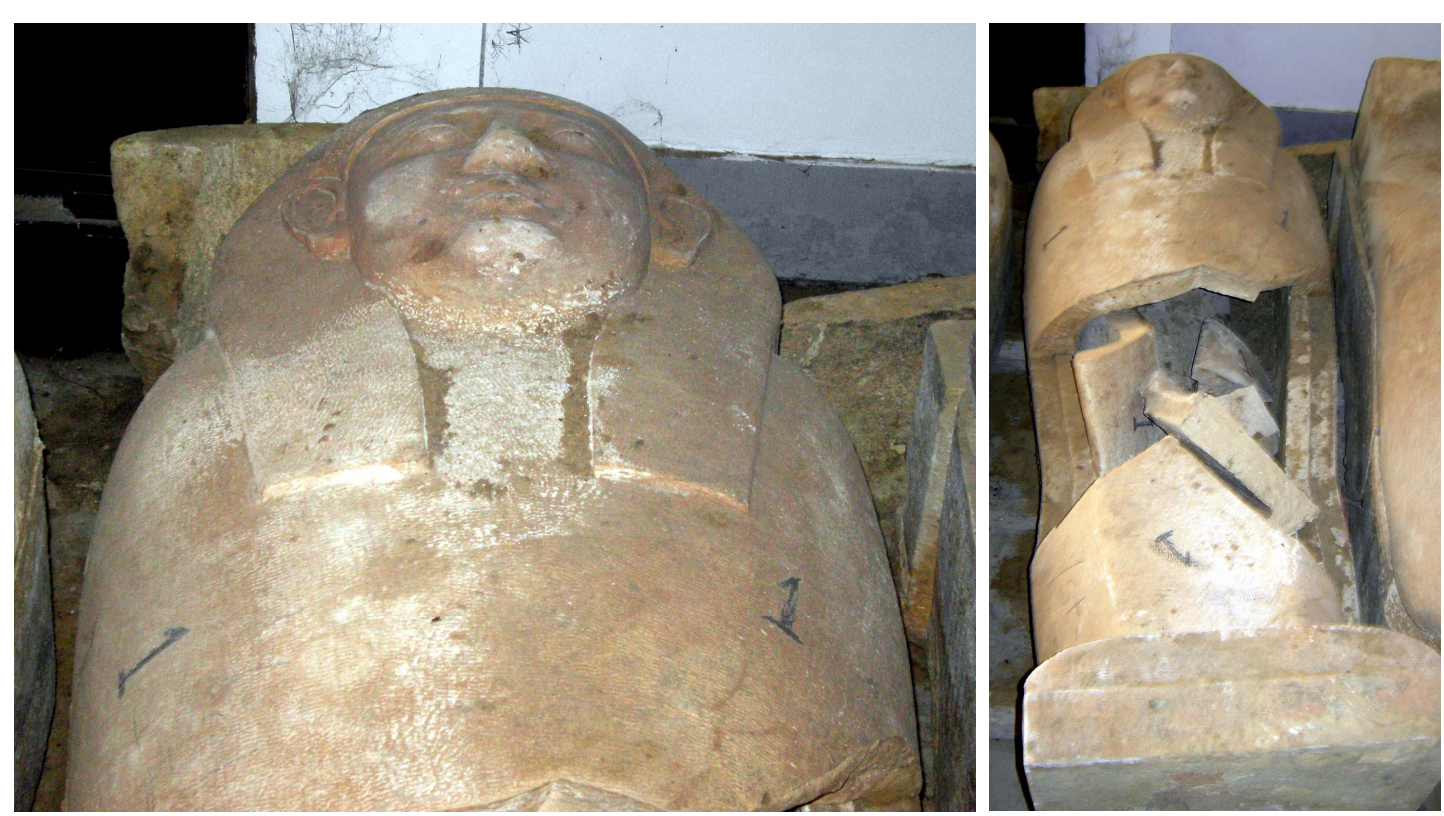

Fig. (3-a) shows deterioration phenomena of the sarcophagus No. (1) For example, the fracture of the cover into seven parts, dirt on the surface and crystallization of salts.

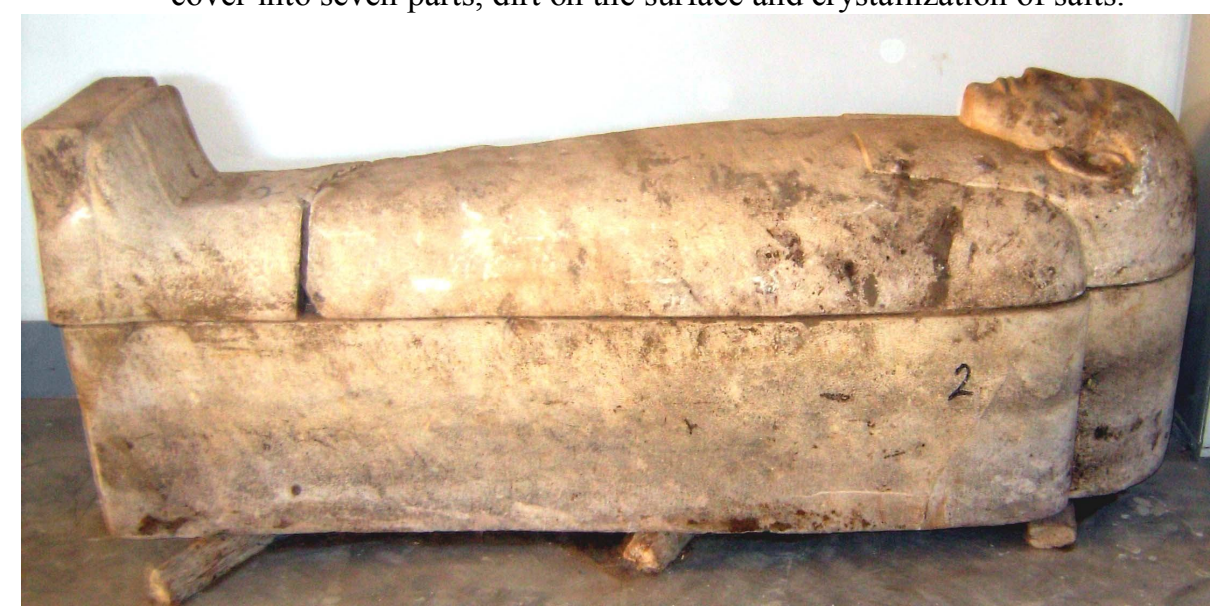

Fig. (3-b) shows dry clay stains; the cover of sarcophagi No. (2) Which was broken into two halves and efflorescence of salts 


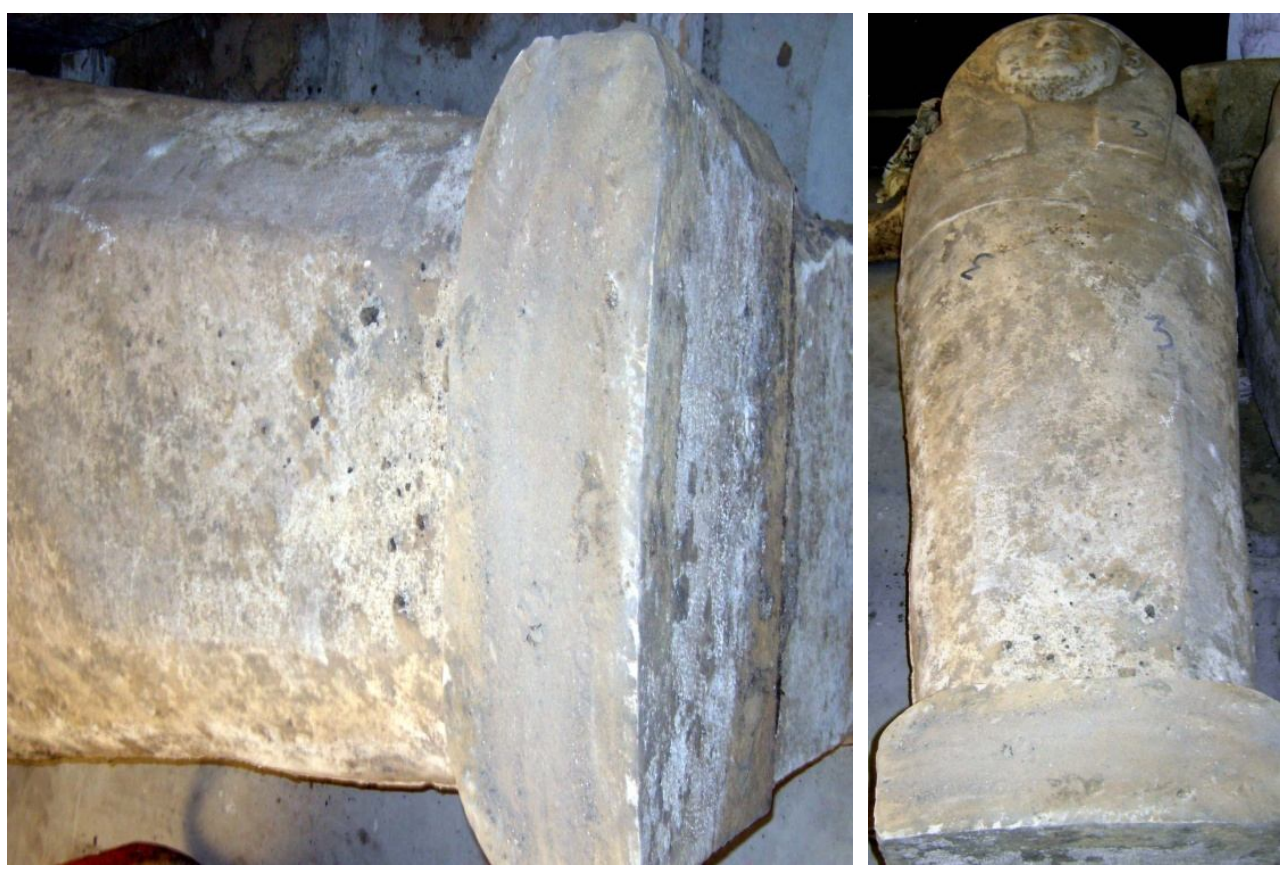

Fig. (3-c) shows crystallization of salts on sarcophagus No. (3) base, clay stains and the cover of sarcophagus was broken into two.
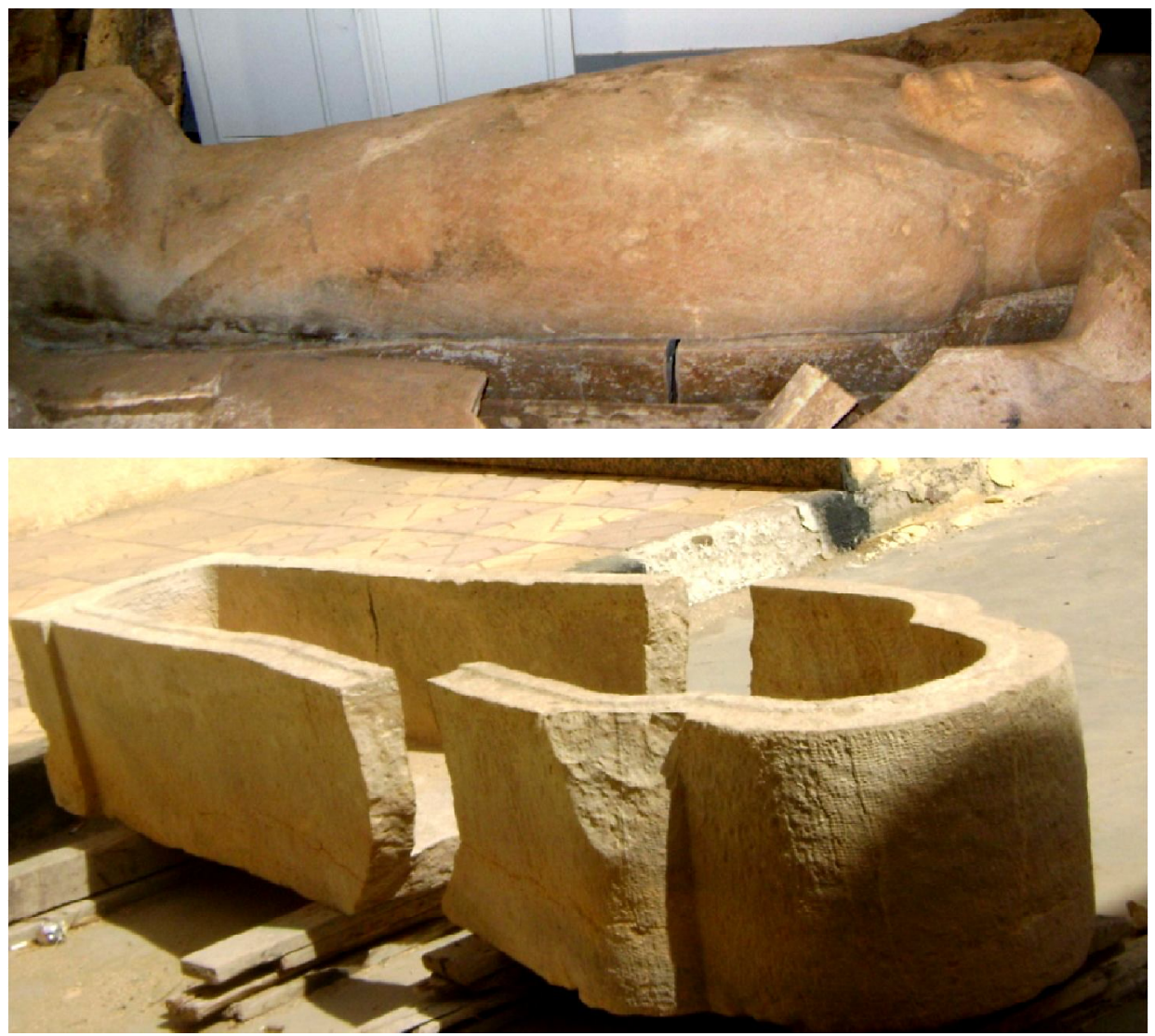

Fig. (3-d) shows the base of sarcophagi was broken into two from the center, crystallization of salts and clay dirt. 


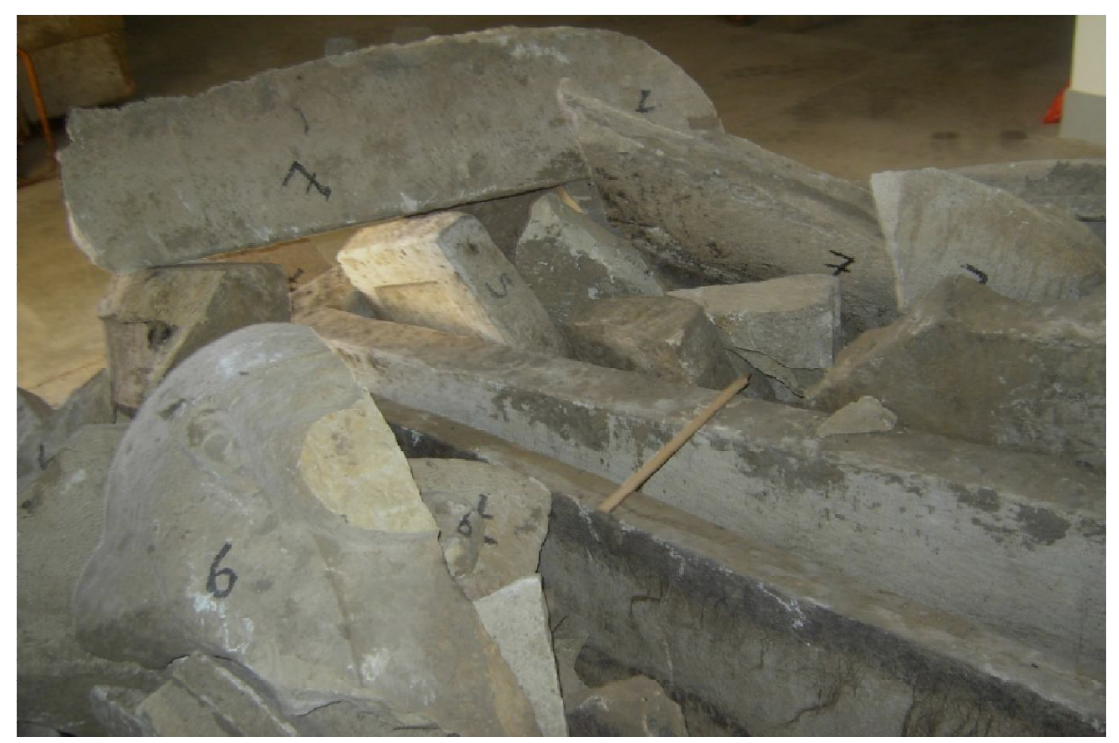

Fig. (3-e) shows the sarcophagi were broken into several parts, stains, clay dirt and crystallization of salts.

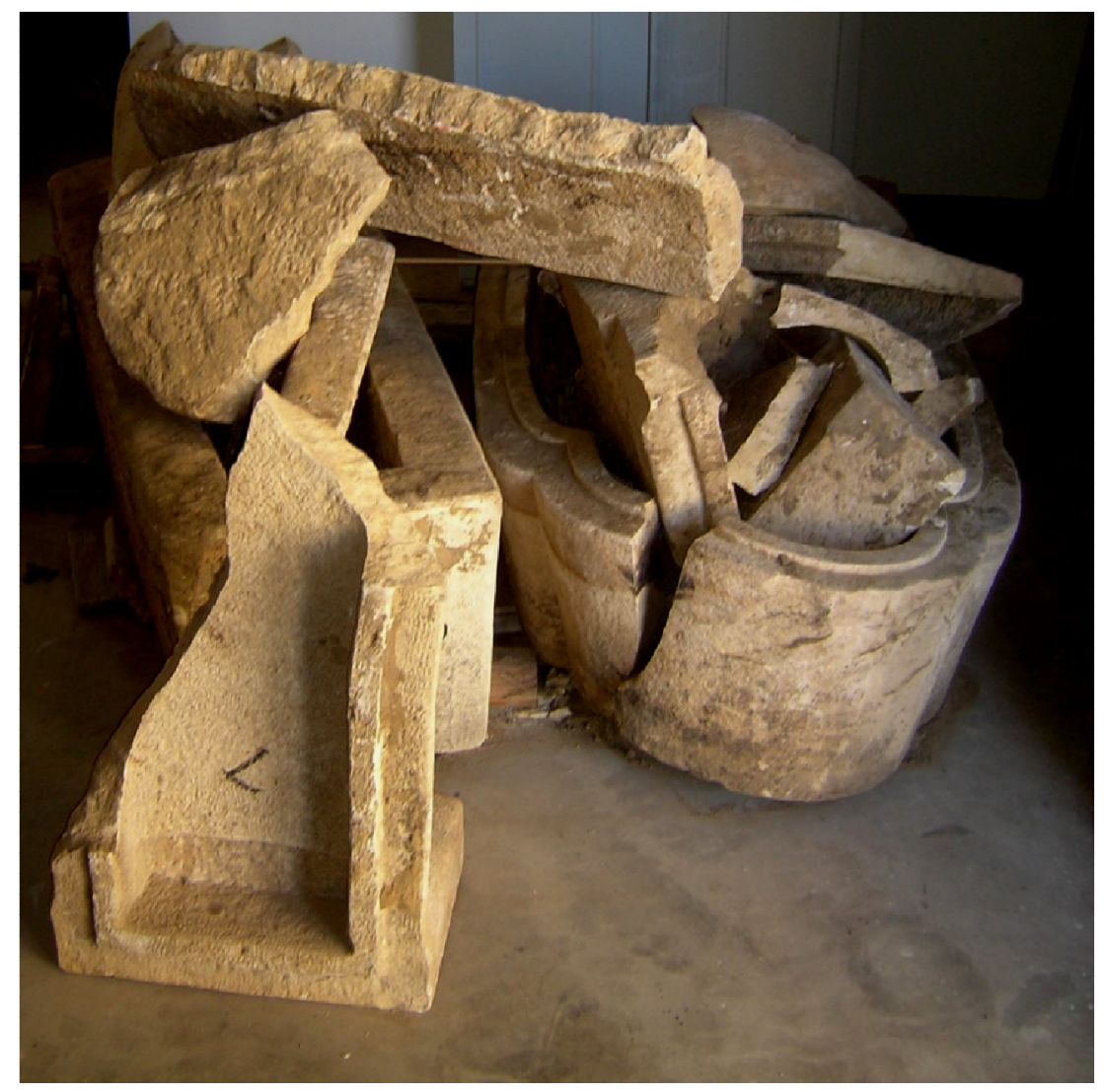

Fig. (3-f) shows dirty surfaces, crystallization of salts and the cover and the base were broken into several parts. 


\section{Materials and Methods}

Limestone samples have been selected from the stone sarcophagi, and then they were examined and analyzed by the polarizing microscope (PLM), model (Olympus BX51 TF Japan, scanning electron microscope (SEM), using (SEM JEOL Japan) X-ray diffraction (XRD) and Energy dispersive X-ray analysis (EDX). X-ray diffractometer (Philips, PW 1840) with Ni-filtered $\mathrm{CuK \alpha}$ radiation at operating conditions of $40 \mathrm{kV} / 30 \mathrm{~mA}$ and a scan speed of $2^{\circ}(2 \theta) /$ min. was used for this purpose. The physical and mechanical analyses have been determined. A chemical analysis of ground water was carried out.

\section{Results:}

\subsection{Polarizing Microscope (PLM)}

Limestone samples have been examined under the Polarizing microscope, it is found that thin sections of Limestone consist mainly of calcite including fossils, iron oxides, clay minerals and some fine grained quartz, fig.(4).

\subsection{Scanning Electron Microscope (SEM)}

When limestone samples are examined using (SEM), it is found that the crystals were worn out by the effect of the dissolving of some components. Samples lost the binding materials between grains by the effect of salt crystallization and sources of moisture. The internal structure of stone was deteriorated by the attack of soluble salts which leads to increase in porosity and the loss of cohesion, fig. (5).

\subsection{Energy Dispersive X-ray analysis (EDX)}

The results of the limestone sample shows that it consists of calcium element (Ca) with $41.62 \%$, sulphur element (S) with $13.12 \%$, Silicon element (Si) with $7.18 \%$ and Sodium element $(\mathrm{Na})$ with $7.28 \%$ in addition to traces from other elements, table No. (2) and Figure No. (6)

Table No. (2) Shows the result of EDX analysis of Limestone sample.

\begin{tabular}{|l|c|c|c|c|c|c|c|c|c|}
\hline Element & Na & Mg & Si & S & Cl & K & Ca & Fe & Total \\
\hline Percentage \% & 7.28 & 1.51 & 7.18 & 13.12 & 21.12 & 3.24 & 41.62 & 4.93 & 100 \\
\hline
\end{tabular}



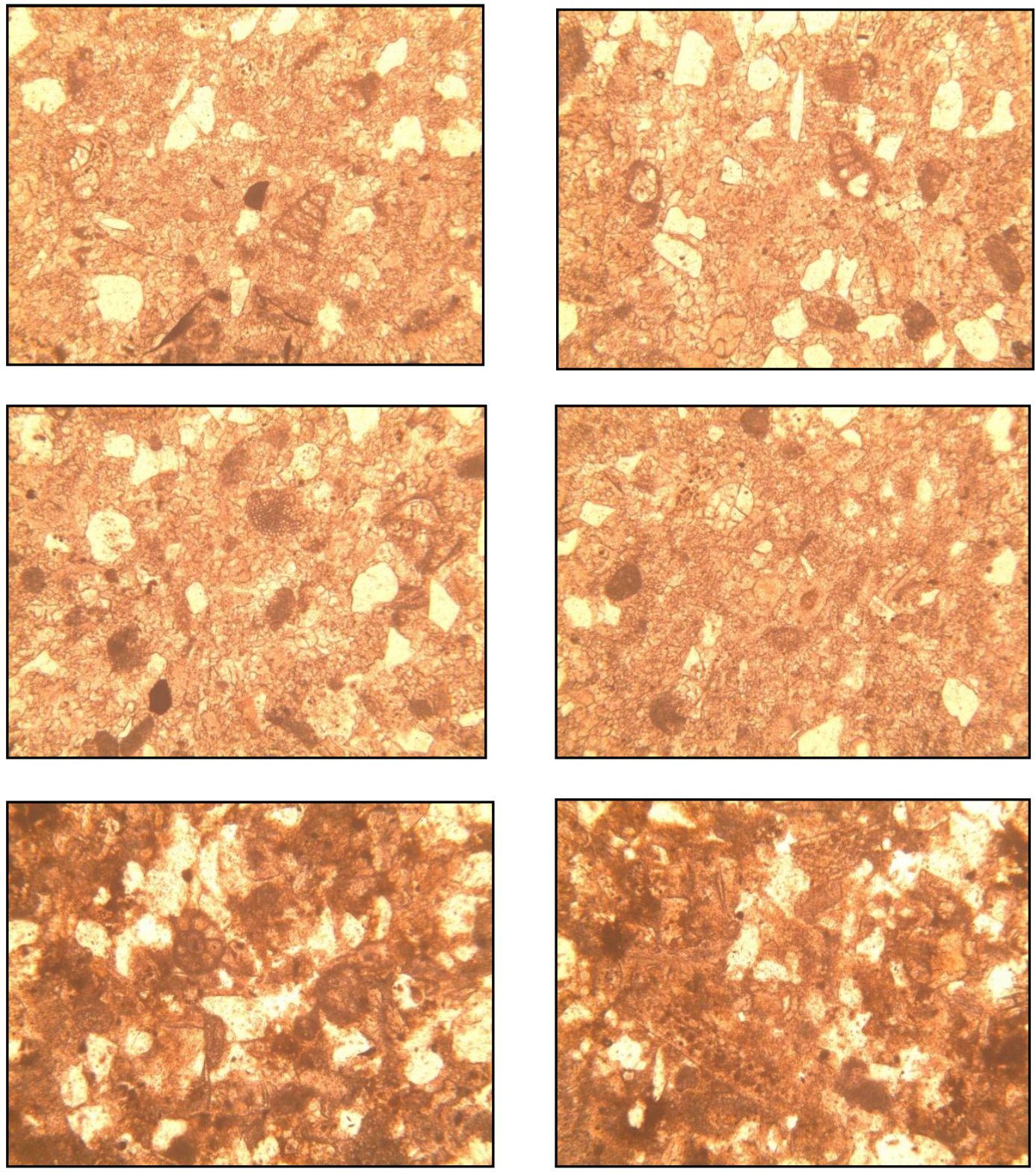

Fig. (4) Thin section photomicrographs showing iron oxides, clay minerals, fossil and grains of quartz in a mass ground of fine- grained calcite. $4 \mathrm{X}$ (C.N).
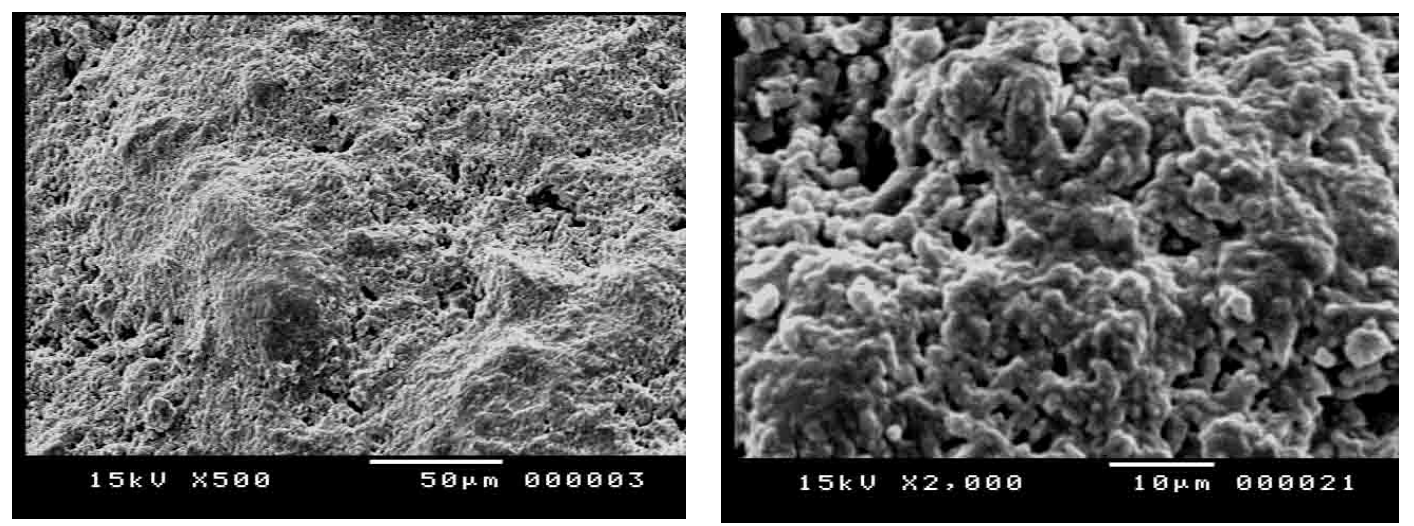

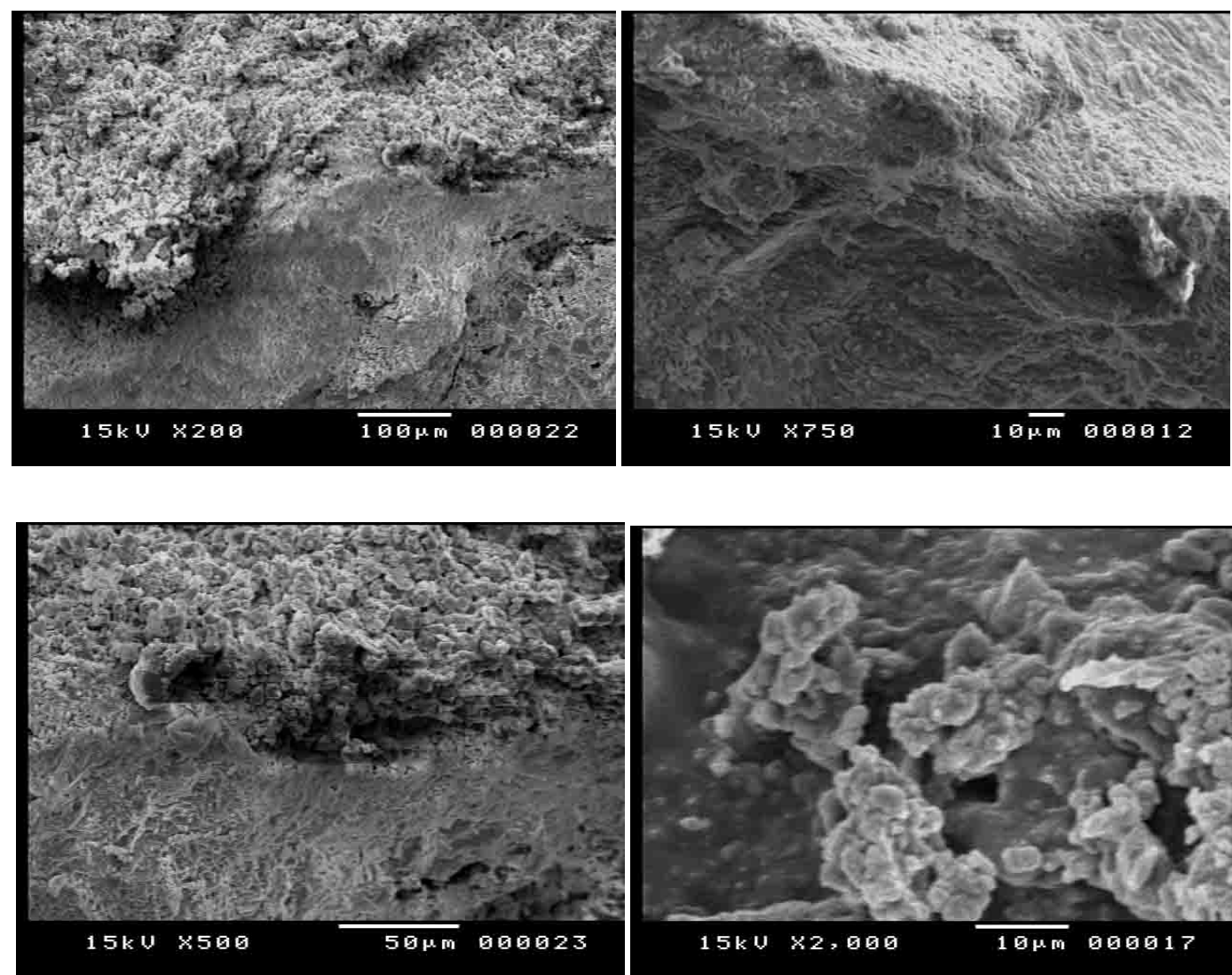

Fig. (5) SEM photomicrographs show disintegration between grains voids, dissolving of some component of stone.

\subsection{X-ray diffraction (XRD)}

Data of X-ray diffraction of limestone samples shows that the sample consists mainly of calcite mineral, Card No. (5- 0586), Dolomite mineral card No. (11- 078), Halite mineral card No. (5-0628) in addition to Gypsum mineral, Card No. (6-0046), and Quartz figs. No. (6), (7).

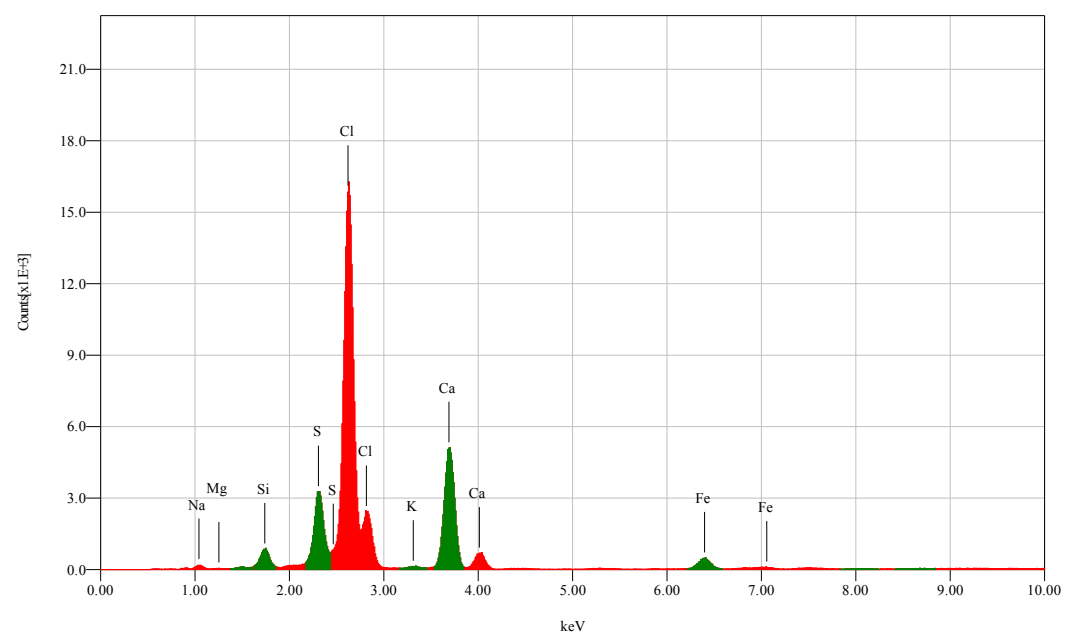

Fig. (5) Shows EDX pattern of limestone Sample. 


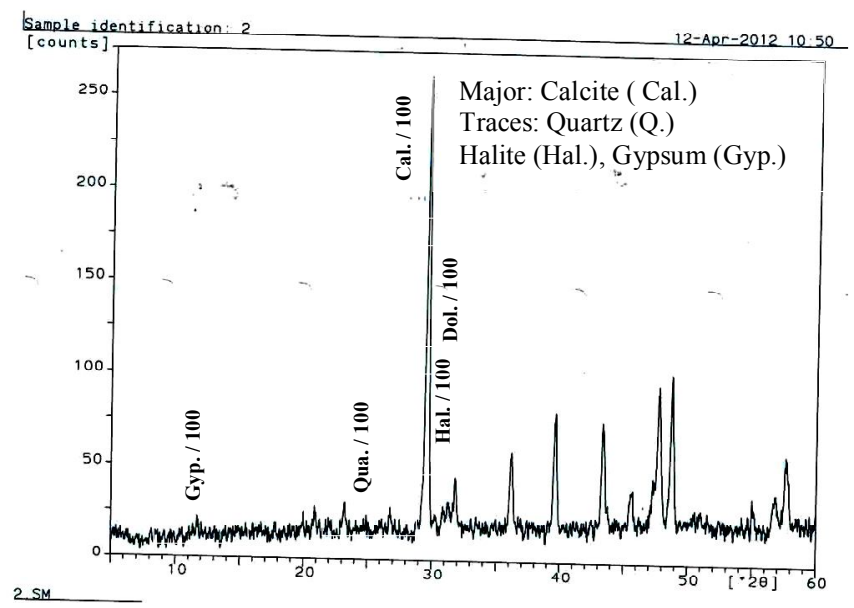

Fig. (6) shows XRD pattern of limestone sample from the stone sarcophagi.

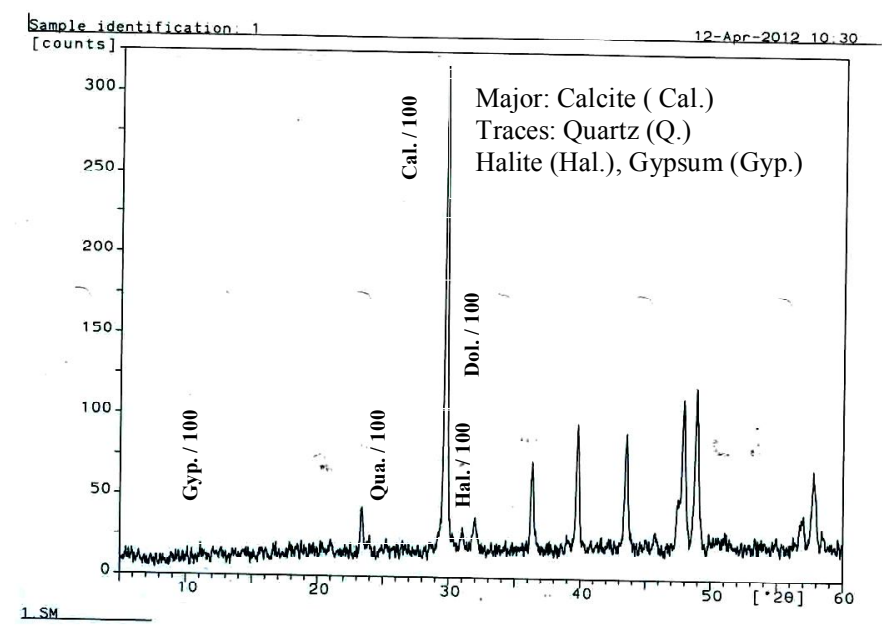

Fig. (7) shows XRD pattern of limestone from the stone sarcophagi.

\subsection{Chemical analysis for ground water}

A chemical analysis of the ground water sample from the excavation site shows that halite $(\mathrm{NaCl})$ was found with a high percentage (1952), the total chemical analysis of this sample is shown in table No. (3)

Table No. (3) Shows the results of the chemical analysis of underground water from the site.

\begin{tabular}{|c|l|c|c|}
\hline No. & \multicolumn{1}{|c|}{ Chemical compound } & Molecular formula & Result (Pmm) \\
\hline 1 & Total mineral soluble & Ionized salts & 3269 \\
\hline 2 & Alkalinity as sodium carbonate & $\mathrm{NaHCO}_{3}$ & 479 \\
\hline 3 & Salinity as sodium chloride & $\mathrm{NaCl}$ & 1952 \\
\hline 4 & Sulphates as sulphur trioxide & $\mathrm{SO}_{3}^{--}$ & 322 \\
\hline 5 & PH value & $\mathrm{Log} \frac{1}{H}+$ & 7.5 \\
& & & \\
\hline
\end{tabular}

5. Restoration and Conservation Processes of the Stone Sarcophagi Dirt and clay stains were removed mechanically using brushes, scalpels and spatulas. ${ }^{10}$ Salts which crystallized on the surfaces were removed mechanically by manual tools. ${ }^{11}$ Soluble salts were extracted by poultices. A poultice consists of 
bentonite and sand at ratio 1: 2. Poultices components have placed on the stone surfaces and covered with poly ethylene sheets and were left for two days until the stone surfaces were dried then the poultices components were removed by manual tools. ${ }^{12}$ Stone surfaces were washed with distilled water. The process was repeated until salts were extracted. ${ }^{13}$ Stainless steel rods were used with Araldite and limestone powder to reinforce, fix and collect the disintegrated parts. Epoxy resin was used for fixing friable parts. Epoxy (EP 2101) is suitable for this purpose. It is a cyclo-aliphatic epoxy. ${ }^{14}$ The resin is available commercially as a $25 \%$ solution in a mixture of isopropanol and toluene. The hardener K 2102 is an aliphatic polyamine that is mixed with the resin 1: 2 by weight. Once the two components are mixed, a temperature dependent induction time is required before application. At $20 \mathrm{C}$ this time varies from $2-8$ hours. ${ }^{15}$ The cleaning process was carried out for disintegrated parts before collecting process. A Piece of cotton with iron oxide pigment were used to determine the position of stainless steel rods on the surface of fracture parts. ${ }^{16}$ Electric drills were used in the collection process. ${ }^{17}$ Completing the missing parts was carried out using limestone powder mixed with lime and fine sand with 0.5: 1: 3 on order. Consolidation processes were carried out using ethyl silicate. ${ }^{18}$ Methyl tri-methoxy silane was used in isolation of the stone sarcophagi surfaces against moisture, figs. (8 $-15){ }^{19}$
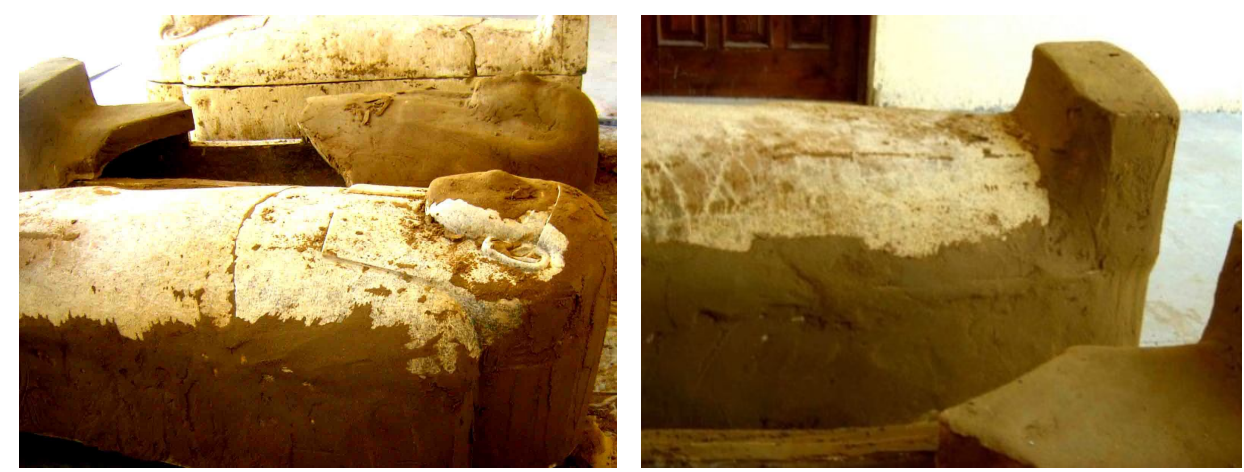

Fig. (8) shows extraction of soluble salts from the stone sarcophagi using bentonite poultices.

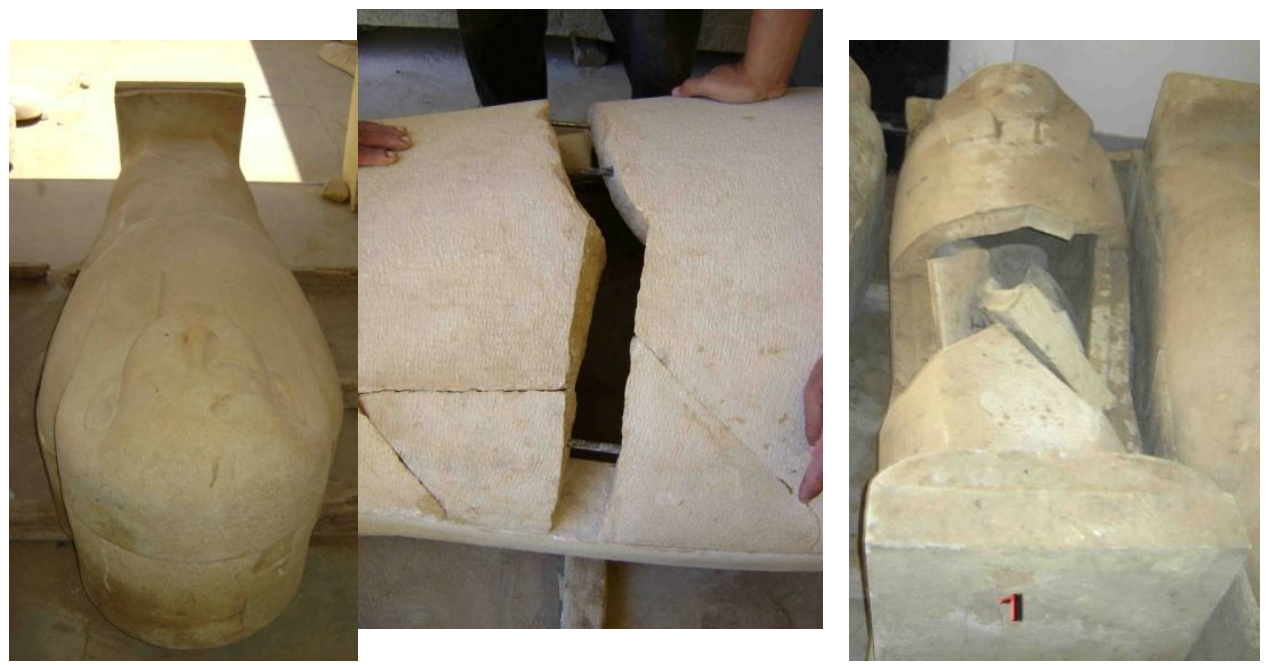

Fig. (9) shows the stone sarcophagi no.(1) before, during and after restoration and conservation processes. 

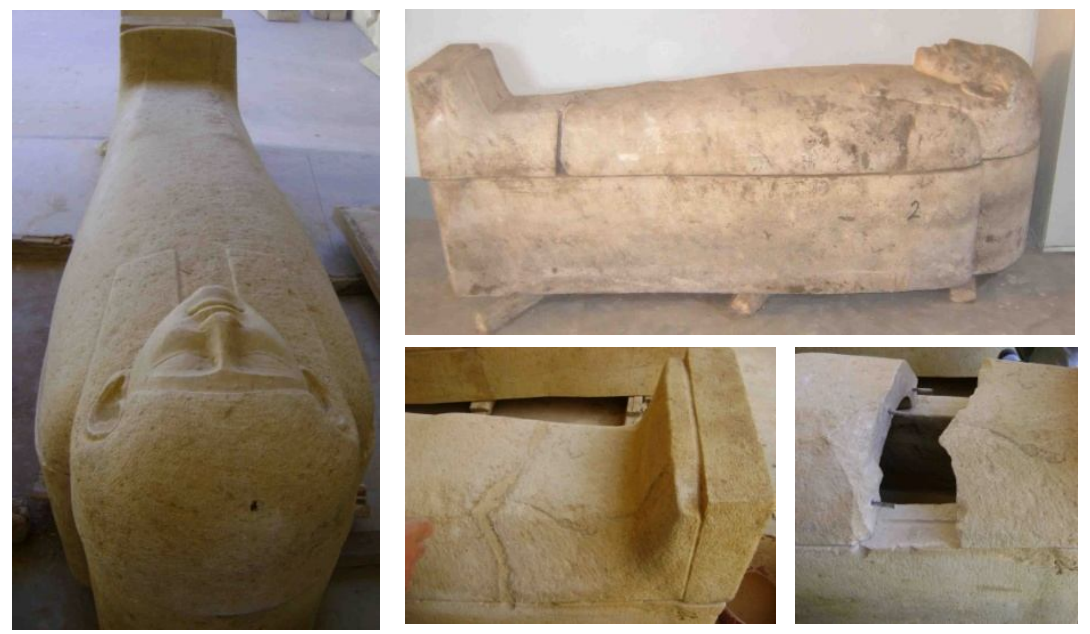

Fig. (10) shows the stone sarcophagi no.(2) before, during and after restoration and conservation processes.
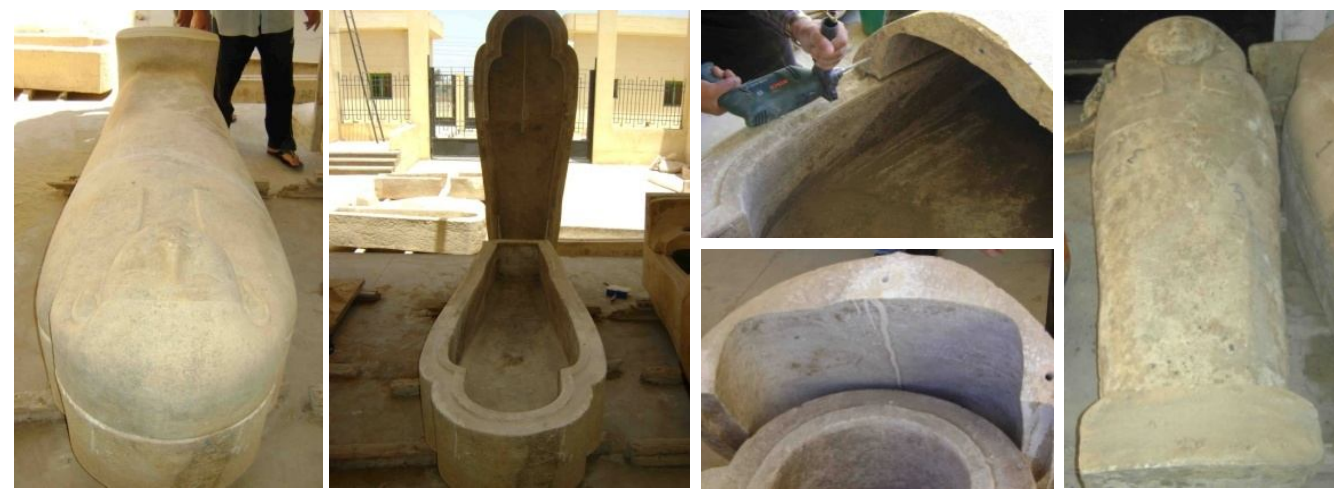

Fig. (11) shows the stone sarcophagi no.(3) before, during and after restoration and conservation processes.
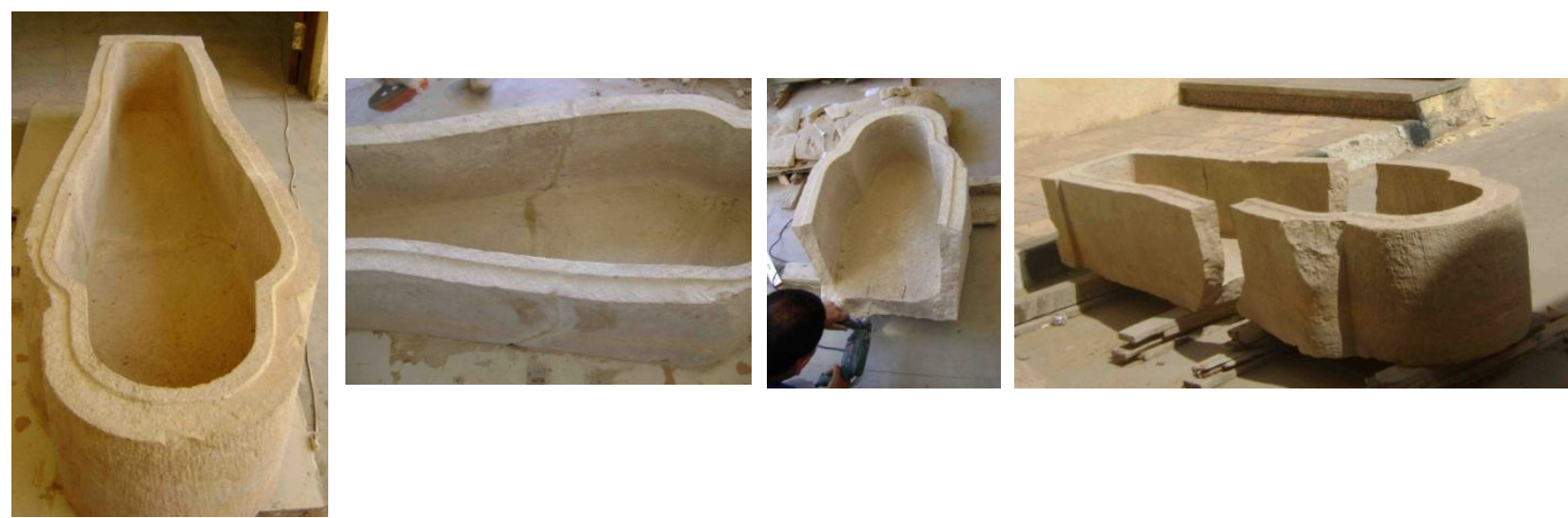

Fig. (12) shows the stone sarcophagi no.(4) before, during and after restoration and conservation processes. 

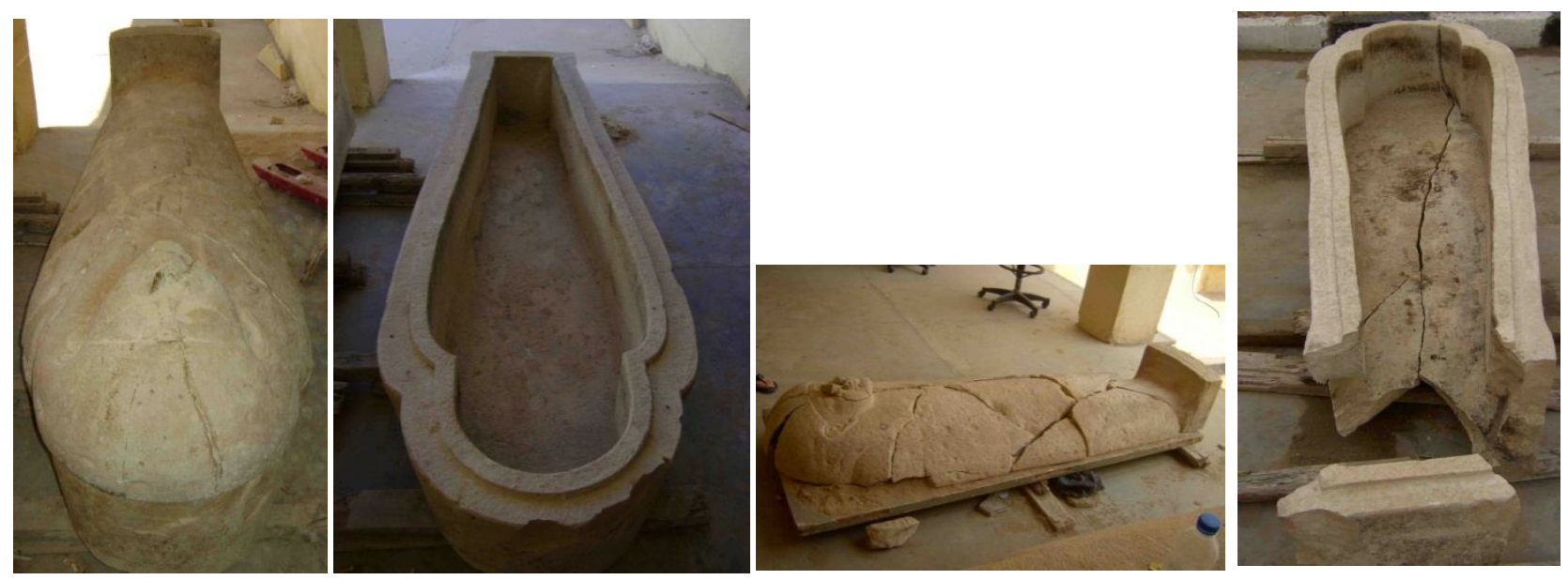

Fig. (13) shows the stone sarcophagi no.(5) before, during and after restoration and conservation processes.
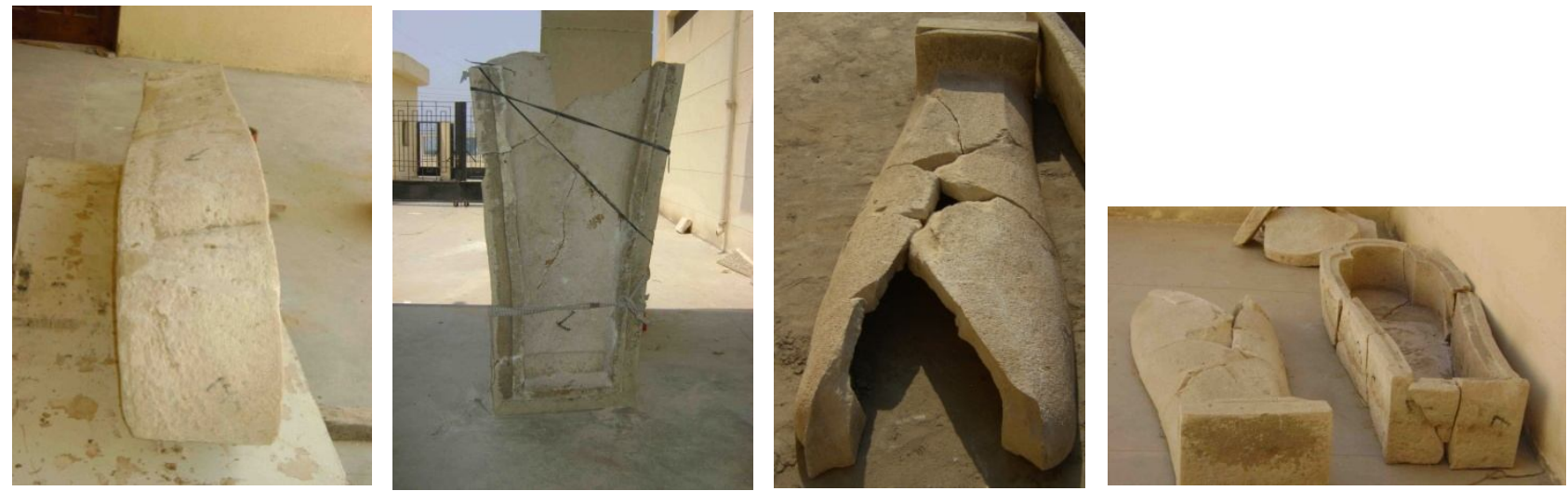

Fig. (14) shows the stone sarcophagi no.(6) before, during and after restoration and conservation processes.
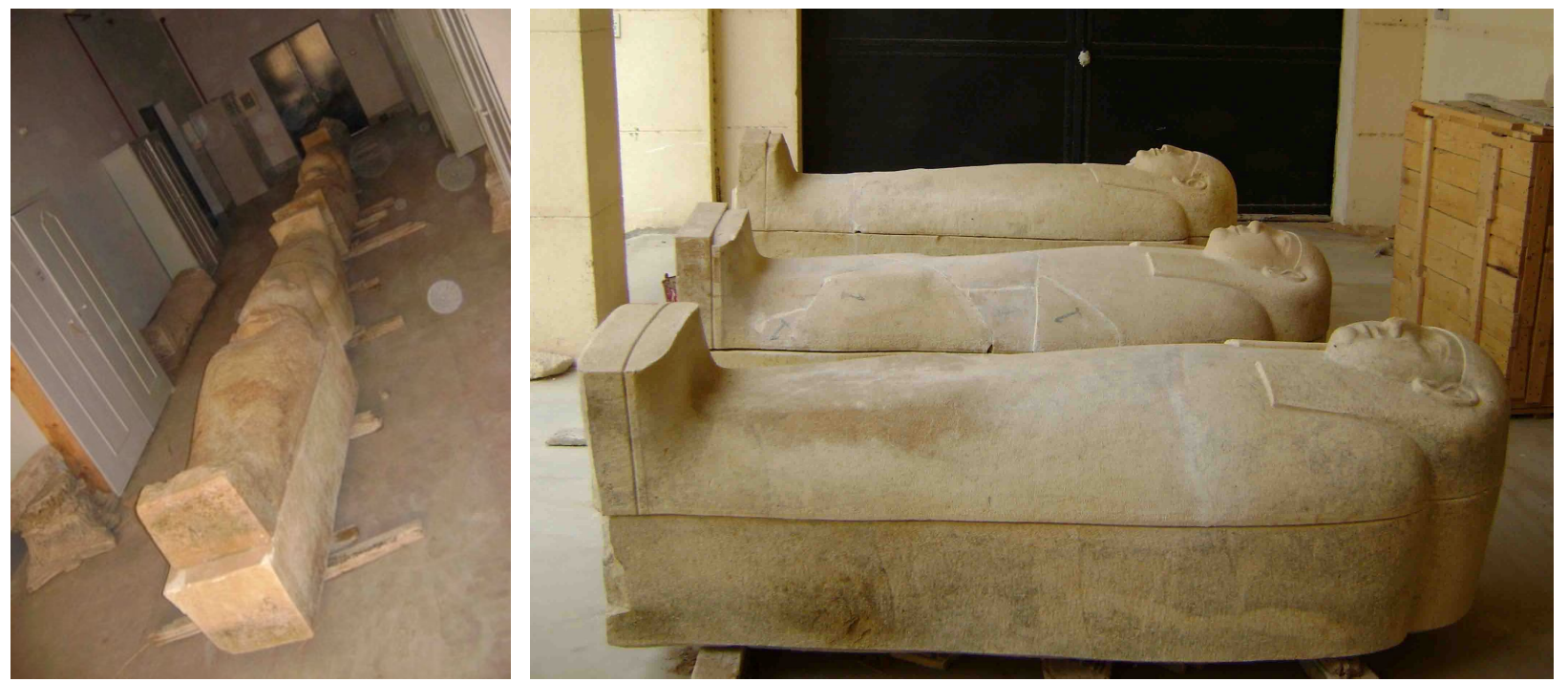


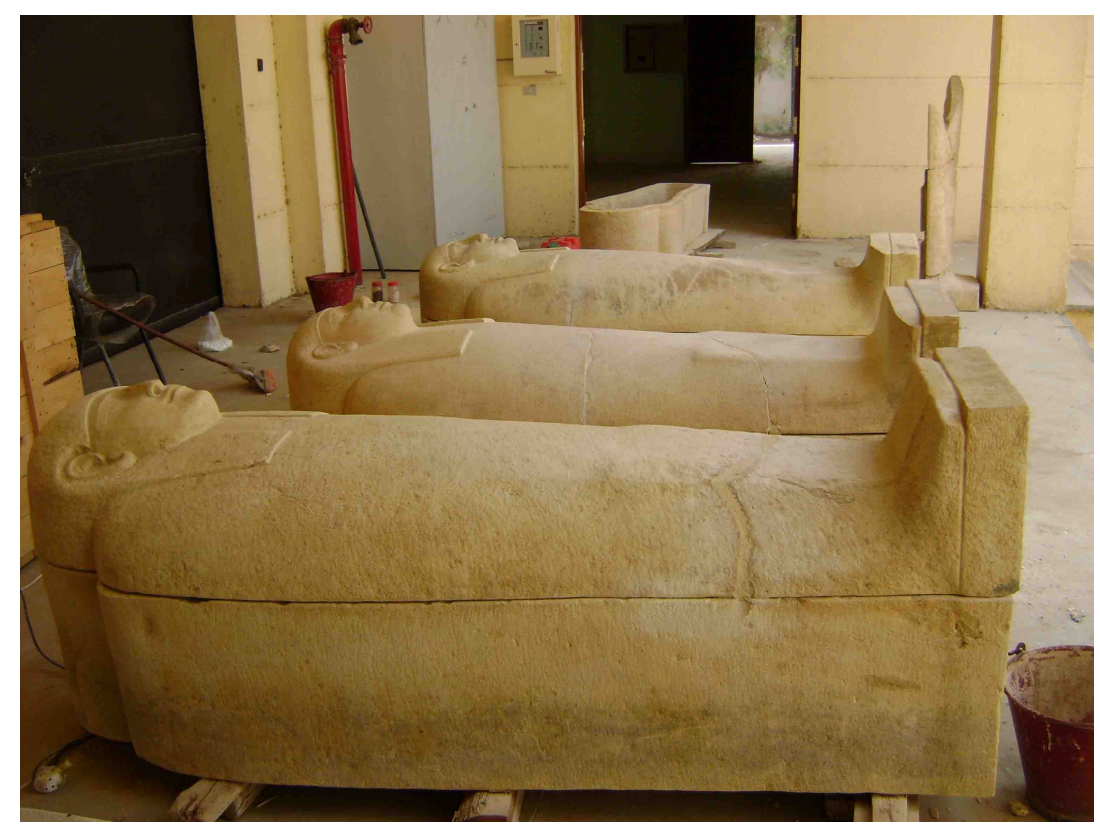

Fig. (15) shows the stone sarcophagi after restoration and conservation processes.

\section{Discussion:}

The stone sarcophagi suffered from weathering phenomena that reflect various environment factors. The X-ray analysis as well as petrography studies indicate that the mineralogical composition in susceptible to weathering and deterioration by salts that comes from the burial environmental conditions. ${ }^{20}$ The rock porosity enables salts to invade deeply within the rock texture, consequently more and severe deep weathering physically and/or chemically is expected. ${ }^{21}$ SEM shows the disintegration of calcite crystals and the dissolution of the internal micro texture of the limestone, this facts leads to an increase of porosity and loss of cohesion of the stone, and the grains are loose from each other. In a burial environment, the stone sarcophagi were decayed by physical and chemical processes. ${ }^{22}$ The stone is physically affected by saturation with water soluble salts, abrasion and stone will also be adversely affected by acids and other substances in the ground water. ${ }^{23}$ Changes will be resumed as soon as the stone sarcophagi were uncovered in the ground and were suddenly exposed to new environment conditions. From the moment which the stone sarcophagi were exposed to air, the process of deterioration begun again and may be obvious after as little time as a few seconds. The most damaging feature of excavation is the change in the water content of their environment. Those exposed to damp or wet deposits suffer from loss of water and those from extremely dry conditions from the presence of water. The loss of water during the excavation can have several deterioration effects. Probably the most notorious damage is due to soluble salts. ${ }^{24}$ When the solution in the pores finally dries out after excavation, the salts crystallize. Damage occurs where the salt solution is so concentrated that the crystals fill up the pores exerting, as they grow, enormous pressure on the walls of the pores. Water is the most aggressive agent in deterioration of stone sarcophagi, which acts as a vehicle for weathering processes. Water dissolves and transports soluble salts within the stone causing efflorescence on the surface of the stone. ${ }^{25}$ The salt crystallization and hydration processes lead to loss of cohesion between grains and causes the spalling, detachment of individual grains, pushing surface layer of stone, different types of cracks, powdering, crumbling with possible appearance of white efflorescence of salts, high failure, fragile and flaking, 
exfoliation, detachment of the superficial layers and granular disintegration into powder. ${ }^{26}$ According to deterioration phenomena of the stone sarcophagi and their status state the restoration processes were carried out. Restoration and conservation processes included mechanical and chemical cleaning, extraction of salts, collecting the disintegrated parts, completing the missing parts, consolidation and isolating processes. Conservation processes are very important for protection the stone sarcophagi from further deterioration and degradation.

\section{Conclusion:}

Examinations and analyses were sufficient to identify the deterioration factors that had affected the stone sarcophagi. Thus, these objects exposed to many deterioration factors in the burial environment which the stone sarcophagi were in direct contact with soil. The soil properties and its solution played an important role in the deterioration and degradation of the stone sarcophagi. The presence of Halite Salt $(\mathrm{NaCl})$ in rising groundwater leads to dramatic changes of the stone sarcophagi, many cracks and broken parts of the stone sarcophagi as a result of the opening process. On the other hand, one of the important deterioration factors was the transferring process of these stone sarcophagi from tel el-deir site to tel el - raba site besides, the opening process of the stone sarcophagi at the excavation site. Extraction of soluble salts from the stone sarcophagi was carried out using bentonite poultices. Epoxy resin was used for collecting the disintegrated parts. Consolidation processes were carried out using ethyl silicate. Methyl tri-methoxy silane was used in isolation of the stone sarcophagi surfaces against moisture.

\section{Notes:}

${ }^{1}$ Atlas of archaeological excavations places in Damietta, the Supreme Council of Antiquities, 2002.

${ }^{2}$ Tel El-Deir (têl äl-dịr) Excavation Report, Damietta, Supreme Council of Antiquities, Egypt, May, 2005.

${ }^{3}$ Chesworth, Ward, (ed.), Encyclopedia of soil science. Dordrecht, Netherlands: (Springer, 2008). 22-23

${ }^{4}$ McCarthy, David F., Essentials of Soil Mechanics and Foundations: Basic Geotechnics (2 ${ }^{\text {nd }}$ edition). Reston, Virginia: (Reston Publishing.1982), 12-15.

${ }^{5}$ Brown R. B., "Soil Texture", Fact Sheet SL-29, University of Florida, (Institute of Food and Agricultural Sciences 2003), 45- 55.

${ }^{6}$ Brady, Nyle, The Nature and Properties of Soils ( $9^{\text {th }}$ edition). USA: (Macmillan Publishing Co.1984). 4-7.

${ }^{7}$ Michael E. Ritter, Factors Affecting Soil Development, Soil Systems, The Physical Environment: an Introduction to Physical Geography, University of Wisconsin, (Stevens Point, 1 October 2009), 78- 82. ${ }^{8}$ Gilluly, Waters Woodford, Principles of Geology, (4 ${ }^{\text {th }}$ edition). USA: (W.H. Freeman 1975), 215.

${ }^{9}$ Kohne, John Maximilian \& Koehne Sigrid, Simunek Jirka, "A review of model applications for structured soils: a) Water flow and tracer transport". Journal of Contaminant Hydrology 2009 (104), 14.

${ }^{10}$ Maxwell, I., "Stone cleaning: For better or worse? An overview", in R. G. M. Webster (ed.), Stone Cleaning and the Nature, Soiling and Decay Mechanisms of Stone; Proceedings of the International Conference Held in Edinburgh, UK, 14-16 April 1992, London, (Donhead Publishing, 1992), 3 - 49

${ }^{11}$ Verges-Belmin, V., "Towards a definition of common evaluation criteria for the cleaning of porous building materials: A review", Science and Technology for Cultural Heritage 5; 1 (1996), 69 - 83.

${ }^{12}$ Verges-Belmin, V. \& Siedel H., "Desalination of masonries and monumental sculptures by poulticing: A review", Bauinstandsetzen und Baudenkmalpflege: Eine international Zeitschrift 11 (2005), $391-408$. 


\footnotetext{
${ }^{13}$ Fassina, V., General criteria for the cleaning of stone: Theoretical aspects and methodology of application, in F. Zezza (ed.), Stone Material in Monuments: Diagnosis and Conservation; Scuola universitaria C.U.M. conservazione dei monumenti, Heraklion, Crete, 24-30 May 1993, Bari: (Mario Adda Editore, 1994), 131 - 38

${ }^{14}$ Luan Xiaoxia, Chunchun Xu, Zise Wang, and Jing Ji, "Preservation effect of modified waterborne epoxy resin emulsion for stone historical relic", Corrosion \& Protection 29-8 (2008), 451 - 53.

${ }^{15}$ Cardiano, P., R. C. Ponterio, S. Sergi, S. Lo Schiavo, and P. Piraino, "Epoxy silica polymers as stone conservation materials", Polymer 46 -6 (2005), 1857 - 1864.

${ }^{16}$ Maxwell I., "Emerging conservation issues in consequence of cleaning Scottish historic buildings", in J. Riederer (ed.), Proceedings of the 8th International Congress on Deterioration and Conservation of Stone, Berlin, 30 Sept.-4 Oct. 1996, Berlin: (Moller Druck und Verlag, 1996), 1405-1414.
}

${ }^{17}$ Smith, B. J., Gomez-Heras, M. \& Viles, H. A., "Underlying issues on the selection, use and conservation of building limestone in Smith, B., Gomez-Heras, M., Viles, H. \& Cassar, J. (eds.), Limestone in the built environment: present-day challenges for the preservation of the past, The Geological Society, (London, 2010), 1-12.

${ }^{18}$ Wheeler, G., "Alkoxysilanes and the consolidation of stone: Where we are now", in J. Delgado Rodrigues and J. M. Mimoso (eds.), Stone Consolidation in Cultural Heritage: Research and Practice, Proceedings of the International Symposium, Lisbon, (6-7 May 2008), Lisbon: LNEC (Laboratorio Nacional de Engenharia Civil, 2008), 41 - 52

${ }^{19}$ Wheeler, G., and E. S. Goins, "Alkoxysilanes and the Consolidation of Stone", Research in Conservation. Los Angeles: Getty Conservation Institute, 2005, 191-198.

${ }^{20}$ Rodriguez, N. C., "Salt weathering: influence of evaporation rate", Supersaturation and crystallization pattern, Earth surface processes and landforms 24 (1999), 191- 193.

${ }^{21}$ Kozlowski, R. H. et al, Influence of water contained in porous Limestone on corrosion Atmospheric Environment, (1992), 324- 326.

${ }^{22}$ Briginie, J. M., "Sea water absorption, permeability evolution and deterioration assessment of building stones subjected to marine exposure", in: proceedings of $9^{\text {th }}$ international congress on deterioration, (2000), 18-29.

${ }^{23}$ Beck, K. \& AL-Mukhtar, M., "Weathering effects in an urban environment: a case study of tuffeau, a French porous limestone", in Smith, B., Gomez-Heras, M., Viles, H. \& Cassar, J. (eds.), Limestone in the built environment: present-day challenges for the preservation of the past, The Geological Society, (London, 2010), 103-111.

${ }^{24}$ Rescic, S., Fratini, F. \& Tiano, P., On-site evaluation of the mechanical properties of Maastricht limestone and their relationship with the physical characteristics, in Smith, B., Gomez-Heras, M., Viles, H. \& Cassar, J. (eds.), Limestone in the built environment: present-day challenges for the preservation of the past, The Geological Society, (London, 2010), 203-208.

${ }^{25}$ Scherer, G.W, "Stress from crystallization of salt in Pores", in: Proceedings of $9^{\text {th }}$ international congress on deterioration and conservation of stone, (Venice, 2000), 187-194.

${ }^{26}$ Vitima, I. et al, "Problems of soluble salts in the Monuments of Latvia", in: Proceedings of $8^{\text {th }}$ international congress on deterioration and conservation of stone, Vol.1, (Berlin, 1996), 477- 480. 